\title{
Centralized Outcome-based Assessment Process at MCGILL UNIVERSITY
}

\author{
Nasim Razavinia and Laurent Mydlarski \\ Faculty of Engineering, McGill University \\ nasim.razavinia@mcgill.ca laurent.mydlarski@mcgill.ca
}

\begin{abstract}
Compliance with the Graduate Attributes and Continual Improvement criteria is an essential component of the accreditation of engineering programs in Canada. In response to this requirement, McGill University's Faculty of Engineering established a centralized process in which 1) a uniform organizational structure was established, 2) a set of common graduate attribute indicators was developed, 3) the current Learning Management System (D2L) was integrated into the assessment of the graduate attributes, 4) universal indirect assessments for all programs were designed, 5) consistent data analysis and interpretation processes were implemented, and 6) standardized guidelines for continual improvement were created. The implementation of this process, its strengths, and recommendations to increase its efficiency and sustainability are discussed in this paper.
\end{abstract}

Keywords: accreditation, outcome-based assessment, graduate attributes, continual improvement

\section{INTRODUCTION}

In large institutions, whether they be educational or not, the centralization of services and/or processes has both advantages and disadvantages. Distributed services may result in a level of performance that is both less efficient and less consistent across the organization, in addition to being more difficult to control and requiring larger amounts of personnel and resources. Consolidating units with the comparable objectives and goals may improve efficiency and consistency in the processes, and promotes collaboration, while the organization can benefit from leveraging its personnel. However, a notable downfall is that the process is not tailored to a specific clientele.[2] Having both these positive and negative aspects in mind, the Faculty of Engineering at McGill University established a centralized outcome-based assessment process. The latter is aligned with the Canadian Engineering Accreditation Board (CEAB) accreditation criteria on Graduate Attributes and Continual Improvement [1]. This process is designed to benefit from the strengths of such systems, and to hopefully overcome its weaknesses. The following sections in this paper present the major elements of the outcome-based assessment process that was implemented for all 10 engineering programs at McGill. In addition, this paper describes the strengths of this system and the opportunities to increase its efficiency and sustainability.

\section{ORGANIZATIONAL STRUCTURE}

The Faculty of Engineering at McGill University offers bachelor's degrees in chemical, civil, computer, electrical, materials, mechanical, mining, and software engineering, as well as a new program in bioengineering, which started in 2016. Another program in Bioresource Engineering is offered by the Faculty of Agriculture and Environmental Science. The accreditation of all engineering programs (regardless of home faculty) is overseen by the Faculty of Engineering and is under the purview of the Associate Dean (Academic Programs) therein. However, to ensure that the needs of all departments are met, an organizational structure with membership from all stakeholder groups works closely with the Associate Dean on all matters pertaining to $\mathrm{CEAB}$ accreditation criteria 3.1 (Graduate Attributes) and 3.2 (Continual Improvement). This organizational structure has three levels (Execution and Operations, Management, and Leadership), and is depicted in Fig. 1.

The foundation of this structure consists of the instructors in the Faculty, who are directly involved in the outcomes-based assessments in all (undergraduate) courses for which they are responsible. The most fundamental aspect in the assessment process is the specification of the graduate attribute "course map" for a given course, which indicates the level of each graduate attribute in each course (and which are determined by the instructors). To this end, "Faculty standard course outlines" are provided for all undergraduate Engineering courses. These contain information on the course's curriculum content, graduate attributes (and their definitions), and instructional level. The Faculty standard course outline is presented to the students on the first day of class and the assessment of the graduate attributes are discussed. 
Within each department, a "Department-level Continuous Program Evaluation and Improvement" (DCPEI) committee is formed to oversee the activities relates to CEAB criteria 3.1 and 3.2. The membership in this committee includes the chair of the department, the chair of the department's academic committee, who in some cases also serves as the departmental representative on "Faculty-level Continuous Program Evaluation and Improvement" (F-CPEI) committee, an undergraduate student advisor, an undergraduate student, and an industry representative. The D-CPEI committees are responsible for curriculum assessment and implementation of improvements for undergraduate courses/programs.

At the next level, the F-CPEI committee is chaired by the Associate Dean (Academic Programs). Its membership includes representatives from each academic unit, a representative from the university's Teaching and Learning Services (TLS), the Faculty's pedagogical coordinator, a student (the Vice-President Academic of the Engineering Undergraduate Society), and the Faculty's Accreditation Assessment Specialist. The primary role of this committee is to develop: i) processes and procedures for outcome-based assessment, and ii) policies on continual improvement. The F-CPEI is also mandated to oversee and approve departments' continual improvement decisions and actions.

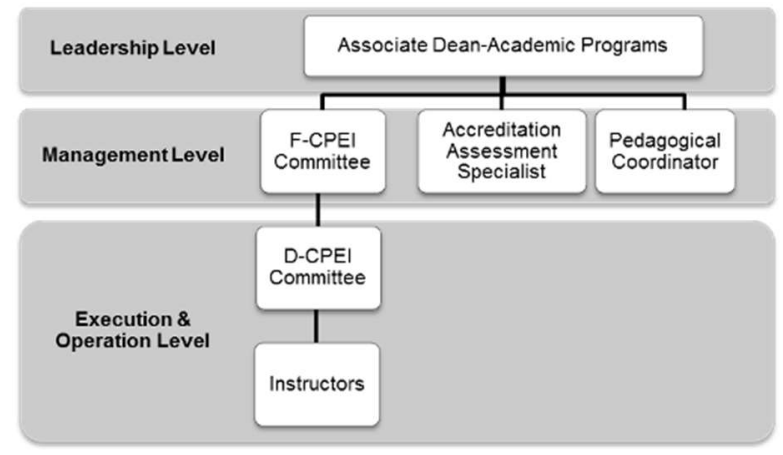

Fig. 1 - GA/Cl Organizational structure

\section{GRADUATE ATTRIBUTE INDICATORS}

The next element in the establishment of a uniform process across Engineering programs was the adoption of common assessment criteria. Although the graduate attributes defined by the CEAB are the basis for assessment, they are not measurable and higher educational institutes are obliged to create measurable assessment criteria (i.e. indicators).

Initially, the Committee on Teaching and Learning (CTL) in the Faculty of Engineering had the responsibility for developing and implementing the processes of graduate attribute assessment and continual improvement, and developed a set of common graduate attribute indicators to be used by all programs [4]. In 2015, these indicators were revised by the Associate Dean-Academic Programs and the Accreditation Assessment Specialist. The revision was deemed necessary because:

i) many of the indicators were hierarchical and were thus not used in the assessments by the instructors,

ii) some indicators were not measurable,

iii) some indicators overlapped multiple graduate attributes,

iv) not all components of their respective graduate attribute were captured, and

v) some indicators were overly general, such that their assessment could not provide valuable results.

The revised indicators were still common to all programs, but each department could modify certain details to customize them if they desired so.

As for any revision to the outcome-based assessment process, the revised indicator list was approved by the F-CPEI committee in the 2014-2015 academic year. It was published on the Faculty's website [3], and was used by all instructors from summer 2015 onward.

\section{DATA COLLECTION APPROACH AND PLATFORM}

With the assessment criteria in place, the F-CPEI committee explored various approaches to establish a uniform process. In 2013-2014, the F-CPEI committee made decisions to assess 4 graduate attributes with a level of D or A in all programs across the Faculty, such that each attribute would be assessed every 3 years for a sample of students.

In 2014-2015, an adjustment to the assessment process was undertaken given that:

1. the administration involved in selecting both samples of courses and students would require more time and effort than simply assessing all students and all courses, and

2. assessment of a graduate attribute once every three years would possibly lack reliable data that could be used for program improvement anytime soon, or ever (considering the frequency of curriculum changes) [4].

The F-CPEI committee, therefore, decided to establish an assessment process in which all graduate attributes in all courses in all programs across the Faculty were assessed for all students.

Given the change in process, the F-CPEI committee then needed to employ a common data collection platform for the direct assessments with the objective of having all data collected in a uniform format so as to facilitate its analysis. In 2014, three pilot projects were initiated to assess the capability of D2L, the university's Learning Management System (LMS), for the

CEEA17; Paper 090

University of Toronto; June 4-7, 2017 
measurement and reporting of graduate attributes in direct assessments [4]. During pilot projects undertaken in the preceding years [4], the instructors were given directions on how to record the results of the direct assessment of graduate attribute indicators. $70 \%$ of the instructors in these courses followed the instructions either completely or partially. For the courses in which instructors fully recorded the assessments, basic calculations and reporting could be performed in the LMS. It was concluded that if the LMS was set up accurately, it could accommodate our needs for recording the graduate attribute data (but not for its analysis). The use of the LMS was subsequently approved by the F-CPEI committee for the purpose of recording the data related to the measurement of the graduate attribute indicators. To assist instructors and teaching assistants, the Accreditation Assessment Specialist organized training and workshops within the Faculty, prepared a website in which documents and videos were developed, and gave presentations in each department. In 2015/16, the result was an $85 \%$ participation rate of instructors across the Faculty. In many cases, the remaining $15 \%$ consisted of cases in which the LMS was not a suitable tool for the assessment of graduate attributes. Examples of such courses were co-op work term courses, capstone design project courses, and research project courses. In such courses, industry advisors/project supervisors/research advisors also evaluate the performance of students instead of, or in addition to, the instructor in charge. Moreover, given that the LMS is only available to McGill instructors, industry advisors have to provide their evaluations by other means, thus creating two systems of assessment for a course. To facilitate the process for the instructors of certain courses, the F-CPEI committee acknowledged that the recording of graduate attribute data can be performed in other ways. However, even in such cases, the instructors were encouraged to use the LMS, if it were feasible, to reduce the workload on the instructors in the analysis of the data.

\section{INDIRECT ASSESSMENTS}

Indirect assessments (such as surveys and selfassessments that provided insight on the students' attainment of the graduate attributes) were also established at the Faculty level. They were constructed to verify that:

1) the courses in curricula are providing the necessary skills to meet the programs' objectives and missions (Internal stakeholder feedback)

2) the knowledge provided to graduates of each program is appropriate to the changing needs of industry, based on input from alumni and employers (External stakeholder feedback).

Although individual programs and instructors have implemented indirect assessments to evaluate the graduate attributes that are more difficult to evaluate with direct assessment (such as assessments using peer feedback to evaluate teamwork), it is essential to ensure that the all programs benefit from the triangulation. Indirect assessments that were developed for all Engineering students are described below.

\subsection{FACC 100/400 Self-assessments}

The assessment used in two Faculty-wide courses (FACC 100: Introduction to the Engineering Profession and FACC 400: Engineering Professional Practice) are focused on the last 6 graduate attributes ("soft skills"): Individual and team work, Communication skills, Professionalism, Impact of engineering on society and environment, Ethics and equity, Lifelong learning. These two self-assessments are identical, but target firstand final-year students. The purpose of these selfassessments is to evaluate students' knowledge at the beginning (FACC 100) and at the end (FACC 400) of their respective programs. Doing so enables a quantification of their progress in these six attributes after four years of engineering education. Approximately 700 students participated in each of these self-assessments. The results were compared with the result of the direct assessment in the same courses for the same graduate attributes. This comparison demonstrated that although students at large meet or exceed expectations in the direct assessments, about $20 \%$ of students feel that their performance level for (the last six graduates attributes is below expectations or marginal. Additional opportunities are being explored to introduce exercises that improve their proficiency in these soft skills.

\subsection{Capstone Design Project Survey}

The Capstone Design Project Survey focused on the effectiveness of each Engineering program in providing students with necessary training, including the application of "Lifelong learning," to fulfill the requirements of their capstone design project. The survey also asks students to evaluate various design considerations in their project. The participation rate varied from one program to another (30\% to $80 \%)$. Some conclusions extracted from this survey are that:

1) students could identify all the twelve graduate attributes in the required courses in their program.

2) although capstone projects often provide opportunities for students to develop all 12 graduate attributes, the students could not identify some of the opportunities that would contribute to the development of certain soft skills (e.g. Professionalism, Ethics and Equity). However, when they were asked to rank the effectiveness of

CEEA17; Paper 090

University of Toronto; June 4-7, 2017 
the capstone design project in developing or improving the same skills, they ranked it as moderately high or high. This suggests that students require some directions in identifying the soft skills in their projects.

3) lifelong learning was identified as a highly developed skill given that the students were regularly employing various methods to overcome limitations in their knowledge.

\subsection{End-of-Course Evaluations}

End-of-Course Evaluations focused on the level of satisfaction of students with respect to different topics relating to the courses in which they are registered. On average $40 \%$ of registered students participate. In March of 2015, one question was added to the Faculty's official course evaluation to explicitly address the courses' relevant graduate attributes. Students were asked to respond to the following statement: "The course satisfied the Canadian Engineering Accreditation Board $(\mathrm{CEAB})$ graduate attributes criteria identified in the course outline." Fig. 2 summarizes the results of the question regarding graduate attributes for all courses in both the Winter 2015 and 2016 semesters.

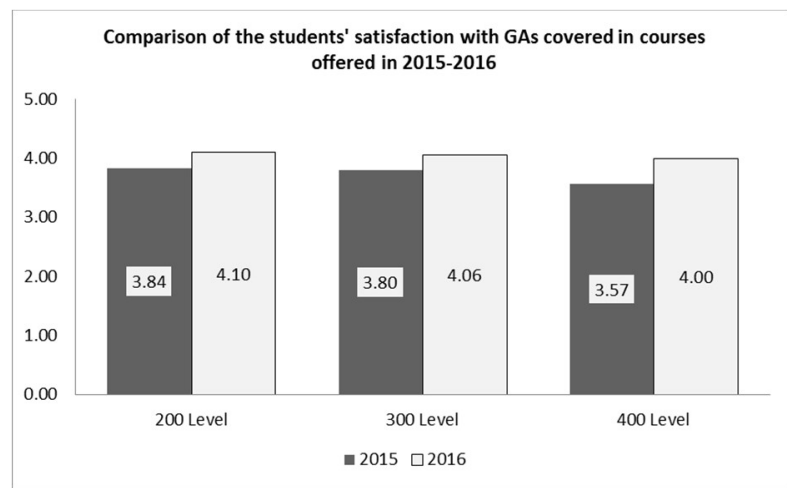

Fig. 2 - Comparison of the students' satisfaction with GAs covered in courses (evaluated on a scale of 1 to 5 )

The results show that the overall level of satisfaction appears to be i) high, and ii) increasing with time. This may be the result of a greater emphasis on identifying the relevant attributes in each course, communicating them to students by the way of the Faculty standard course outline, identification of the graduate attributes on assessment tools in a course, and their communication to the students by the way of the LMS. It may also be related to the greater use of learning activities aimed at developing proficiency in the twelve graduate attributes.

\subsection{Alumni Survey}

An evaluation of engineering programs by recent alumni is conducted by the McGill Engineering Career Center. The Alumni Survey is conducted in February for students who graduated in August and December, and again in July for students who graduated in February. The alumni are asked to rank their level of proficiency in each graduate attribute, as well as their level of satisfaction with both the quantity and quality of the training they received in each graduate attribute in the course of their program of study. The questions are:

1) Having completed your undergraduate Engineering studies at McGill, rate your own perceived level of proficiency in each of the following 12 graduate attributes.

2) Rate your level of satisfaction regarding the quantity of the training you received in your undergraduate Engineering studies at McGill in developing the following 12 graduate attributes

3) Rate your level of satisfaction regarding the quality of the training you received in your undergraduate Engineering studies at McGill in developing the following 12 graduate attributes

The survey results are reported in three categories: "Less than satisfied", "Satisfied", and "More than satisfied". The Accreditation Assessment Specialist analyzes the results for each program, and also reports them to the Associate Dean-Academic Programs and FCPEI committee for review. In the past two years, about $40 \%$ of the recent alumni responded to this survey. Their responses were compared with the programs' learning outcomes. Discrepancies were noted for further monitoring and continual improvement.

\section{DATA ANALYSIS AND INTERPRETATION}

The acquired data on student learning is used to identify program strengths and weaknesses, as related to each of the graduate attributes. Moreover, it is used in making decisions pertaining to program improvements. The subsequent discussion of this analysis is divided into two parts:

1) Data Analysis, and

2) Data Interpretation.

\subsection{Data Analysis}

Data analysis, which occurs at the faculty level, is an important step in the graduate attribute assessment and continual improvement process. It provides information that enables the Faculty and Departments to identify their strengths, as well as opportunities for improvement in the context of the twelve graduate attributes.

Within 4 weeks of the end of each semester, the Accreditation Assessment Specialist provides the departments with the following:

1.Course-level results and analysis pertaining to the

CEEA17; Paper 090

University of Toronto; June 4-7, 2017 
graduate attributes and their indicators: This analysis enables the instructors and the D-CPEI committee to identify: i) gaps in students' learning in the context of the twelve graduate attributes per course, and ii) strength and flaws of the assessment tool(s). It also enables the D-CPEI committee to identify trends and patterns in students' performance in a given graduate attribute (and its indicators).

2. Program-level results and analysis pertaining to graduate attributes and their indicators: This analysis enables the D-CPEI committee to identify: i) gaps in students' learning in the context of the 12 graduate attributes for the program as a whole, and ii) strengths and weaknesses of the program in providing adequate training in the twelve graduate attributes.

Since this is a Faculty-wide process, the analyses are done in a uniform manner for all courses and programs. The benefits are twofold:

1) Since engineering programs consist of courses from various departments, the analysis of courses can vary from one to another program. This makes the comparison of the results in the similar attributes in departmental and non-departmental courses a difficult task. The uniform reporting facilitates the interpretation process.

2) The departments are not dependent on multiple sources to provide them with data. Moreover, the results for service courses that are offered by various departments are analyzed for the students of each program individually. This especially is helpful to the instructors of such courses as they do not have to provide separate analyses of the graduate attributes for students of each program.

\subsection{Data Interpretation}

This part of the process is performed by each department individually. However, the "Threshold" and the "Target" levels for the attainment of each graduate attribute is defined by the Faculty and approved by the F-CPEI committee. To evaluate the performance of students in each graduate attribute, the D-CPEI committee reviews all results and analyses of the direct and indirect assessments. Special consideration is given to the internal and external stakeholders' feedback. The D-CPEI committee interprets the analyzed data (noting trends and discrepancies in data from different sources) based on the expectations of the program in the context of the 12 graduate attributes and the program's learning objectives. The "Target" is that students "Meet" or "Exceed" expectations. The performance of students in the context of the "Target" and "Threshold," as well as anomalous results (e.g. poor performance) are discussed. Consideration is also given to whether the evaluation method(s) of the attribute(s) in specific courses is suitable and accurate. Subsequently, the D-
CPEI informs instructors about the findings and receives their feedback for improvement strategies.

This approach takes advantage of the expertise of each D-CPEI committee members and provides departments with a thorough interpretation of the results to be used for continual improvements.

\section{CONTINUAL IMPROVEMENT}

The continual improvement process is started at the Departmental level and is concluded at the Faculty level.

At the Departmental level, the D-CPEI committee determines the appropriate course- and program-level action plan(s) - immediate/short-term and/or long-term ones - based on the data interpretation. The process starts in June, for implementation in the following year. This offers departments enough time to obtain the approval from the relevant curriculum/academic committees (if required).

The D-CPEI committee prepares a report that is presented on annual basis at the F-CPEI retreat in June. All recommendations presented at the retreat are discussed amongst the members and are voted upon by the F-CPEI committee. All departmental recommendations must also consist of a problem statement that includes the source of findings (i.e. direct/indirect assessments or internal/external consultation), an action plan, necessary resources, and a timeline for implementation of the proposed solutions.

The Chair of the department is responsible for providing the appropriate resources to facilitate implementation of the recommendations. The D-CPEI committee is responsible for re-evaluating recommendations on annual basis and providing the Chair and the F-CPEI committee with a report outlining implemented solutions and their outcomes.

At the Faculty level, the F-CPEI committee monitors the program-level improvement processes and procedures to ensure that they are developed and implemented. The committee also determines the appropriate Faculty-wide action plan(s) based on the analyzed data. This happens through the regular F-CPEI meetings that occur each semester (three times a year). The Accreditation Assessment Specialist prepares the annual continual improvement report indicating the extent to which the action plans were implemented and achieved by each department, the feasibility of the time frames, and recommendation(s) for improving the process. This will be presented by the Associate DeanAcademic Programs at a meeting of Department Chairs in the Fall semester. The Accreditation Assessment Specialist evaluates the data collection process and proposes improvements to achieve a sustainable data collection process. The F-CPEI committee evaluates the proposals and the chair of the F-CPEI committee (Associate Dean-Academic Programs) reports the

CEEA17; Paper 090

University of Toronto; June 4-7, 2017

-5 of $6-$ 
decisions to the Dean for final approval and resource allocation (if required).

\section{CONCLUSIONS}

One positive aspect of a centralized process in the evaluation of the graduate attributes and the subsequent continual improvement process is improved consistency and efficiency, the leveraging of personnel and resources, consistency in the level of performance across the Faculty, and improved monitoring and quality control. The uniform analysis of the data also facilitates the examination and interpretation of the results. Since the data analysis is performed centrally, the faculty members are encouraged to take advantage of the support available. This reduces the workload from each instructor while still keeping them involved during the data collection (for both direct and indirect assessments) and continual improvement processes. Finally, due to the imposed organizational structure, the monitoring/controlling of the improvement actions for all the programs are streamlined.

The negative aspect of centralizing a process is the reduced capability to tailor a process to a given department's needs. However, given that many units were looking for guidance and direction, the imposed centralized process was welcomed, in most cases. Moreover, the role of the D-CPEI committee, who interprets the data and propose the improvement actions, remains unique to a given department.

Our vision for a successful centralized outcomebased assessment process is a straightforward process that minimizes the extra workload on individual instructors while complying with all CEAB criteria. Our aim is to achieve this by promoting a culture of continuous improvement. Because the execution of such a process in and of itself is not sufficient for building and maintaining such a culture, the engagement of the departmental and faculty leadership, instructors' buy-in, continually improving the process, and employing technology to streamline sub-processes are essential. To this end, constant meetings, presentations, and training are offered to the instructors/departments with the goal of bringing more awareness about the necessity of continuous improvement while offering the Faculty's support. This is an on-going effort with the aim to help instructors see the value of the outcome-based assessment.

Another opportunity to increase the efficiency and sustainability of this process is automation of some subprocesses. The Faculty is looking into various methods to automate the data collection, analysis, and reporting processes. At the time of writing, we are in the process of developing software to perform this task.

\section{References}

[1] 2016 Canadian Engineering Accreditation Board Accreditation Criteria and Procedures, pp. 13-16. See https://engineerscanada.ca/sites/default/files/accreditati on-criteria-procedures-2016-final.pdf

[2] Mandernach et al., B. (2015). Transformative Perspectives and Processes in Higher Education (Vol. 6) (A. Dailey-Hebert \& K. S. Dennis, Eds.). Springer. pp. 38-44.

[3] Graduate attribute indicator. (2015). Retrieved from http://www.mcgill.ca/engineering/faculty-staffresources/accreditation/accreditation-resources

[4] Saunders, A. and Mydlarski, L.: Evaluation of graduate attribute assessment and continuous program improvement in the Faculty of Engineering at McGill University", in Proc. CEEA Canadian Engineering Education Conf. (CEEA15), McMaster University, June 2015

CEEA17; Paper 090

University of Toronto; June 4-7, 2017

-6 of $6-$ 